International Journal of

Environmental Research and

Public Health

ISSN 1660-4601

www.mdpi.com/journal/ijerph

Article

\title{
Smoking and the Risk of Upper Aero Digestive Tract Cancers for Men and Women in the Asia-Pacific Region
}

\author{
Alireza Ansary-Moghaddam, Alexandra Martiniuk, Tai-Hing Lam, Konrad Jamrozik, Akiko \\ Tamakoshi, Xianghua Fang, Il Suh, Federica Barzi, Rachel Huxley and Mark Woodward * \\ The Asia Pacific Cohort Studies Collaboration, Mount Sinai Medical School, Box 1087, One Gustave \\ L. Levy Place, New York, NY 10029, USA \\ E-Mails: ansarialireza@yahoo.com (A.A.); a.martiniuk@george.org.au (A.M.); \\ hrmrlth@hkucc.hkuc.hk (T.L.); konrad.jamrozik@adelaide.edu.au (K.J.); tamaa@ncgg.go.jp (A.T.); \\ xhfang163@163.com (X.F.); isuh@yuhs.ac (I.S.); rhuxley@george.org.au (R.H.); \\ fbarzi@george.org.au (F.B.) \\ * Author to whom correspondence should be addressed; E-Mail: mwoodward@george.org.au; \\ Tel.: 212-241-4958; Fax: 212-831-8116
}

Received: 24 December 2008 / Accepted: 1 April 2009 / Published: 3 April 2009

\begin{abstract}
Although smoking is an established causal factor for upper aero digestive tract cancer (UADTC), most of the evidence originates from the West. Thus, we analysed data from 455,409 subjects in the Asia Pacific Cohort Studies Collaboration. Over a median of around six years follow-up, 371 deaths from UADTC were observed. The hazard ratio ( $95 \%$ confidence interval) for current smokers, compared with those who had never smoked, was $2.36(1.76-3.16)$, adjusted for age and alcohol drinking. Tobacco control policies are urgently required in Asia to prevent millions of deaths from UADTC that smoking will otherwise cause.
\end{abstract}

Keywords: Cancer of the pharynx; cancer of the larynx; cancer of the esophagus; smoking; alcohol. 


\section{Introduction}

Upper aero-digestive tract (lip, oral cavity, pharynx, esophagus, larynx) cancers are an important global problem, particularly in developing countries. Since three-quarters of the nearly one million cases of upper aero-digestive tract cancer (UADTC) occurring annually are seen in developing countries, UADTC ranks among the five most common cancers in both men and women in these settings [1]. Whilst there is considerable variation in survival across the constituent cancers in the UADTC group, on average UADTC has one of the lowest figures for five-year survival of all cancers, with a range from $10 \%$ to $65 \%$ [2-4].

Cigarette smoking is a recognised causal factor for UADTC [2-6]. The excess risk of UADTC associated with smoking varies depending on the subtype of cancer and the intensity and duration of smoking [7]. Alcohol drinking is the other main risk factor [3,4,6,7], having been reported to increase the risk of developing UADTC among non-smokers by more than four times [7]. Combined, these two risk factors have been estimated to increase the risk of these cancers by more than twelve times compared with individuals who neither smoke nor drink alcohol [7].

Most of the data examining the aetiological role of smoking on UADTC are derived from studies in Western countries, with few data from populations in eastern and south-eastern Asia (here referred to as "Asia", for brevity). It is not known whether the effects of smoking on the risk of UADTC differ substantially between Asian and non-Asian populations. Region-specific information as to the magnitude of risks associated with these risk factors would assist public health specialists and policy makers in Asia. This is especially relevant, given that the consumption of tobacco in many countries in Asia is very high amongst men [8-10], whilst there is an upwards trend in smoking amongst young women in some of these countries [11]. Furthermore, in countries such as China, where more than $60 \%$ of adult men smoke, the risks associated with smoking are largely unrecognised [9].

The current paper uses data from the largest collaborative study in the region, the Asia Pacific Cohort Studies Collaboration (APCSC), to quantify the risk of mortality from UADTC associated with smoking, taking account of potential confounding and modifying effects from alcohol, in populations of the Asia-Pacific region.

\subsection{Methods}

Details of study identification, data collection and event verification for studies in the APCSC are described elsewhere [12]. Briefly, studies were included if they had continued follow-up for at least 5,000 person-years and had recorded vital status at the end of follow-up. Studies were excluded from APCSC if entry to that study was dependent upon having a particular medical condition; for this current paper only, studies were additionally excluded if they did not record deaths due to UADTC. We restricted our analyses to individuals aged 20 or more years at enrolment. Mortality was classified according to the 9th Revision of the International Classification of Diseases (ICD): UADTC was selected as codes 140-149 (lips, tongue and pharynx; this includes: malignant neoplasms of lip, tongue, major salivary glands, gum, floor of mouth, other and unspecified parts of mouth, oropharynx, nasopharynx, hypopharynx, other and ill-defined sites within the lip), 150 (esophagus), and 161 (larynx). Studies were classified as Asian if their participants were recruited from mainland China, 
Hong Kong, Japan, Korea, Singapore, Taiwan or Thailand; and ANZ if from Australia or New Zealand.

All data on cigarette smoking and alcohol drinking were based on self-report at the time of entry into each of the included studies ('baseline'). Data recorded on smoking included the number of cigarettes currently smoked per day, categorized here into groups of $<20$ and $\geq 20$ (20 cigarettes corresponds to one standard pack), and whether or not non-smokers were former smokers. Alcohol was only recorded as current drinking or not. Participants were included in this study only if they reported their current and past smoking and current alcohol drinking at baseline. In APCSC, 94\% of the 600,445 participants recorded their current smoking status, 92\% recorded their current drinking status and $91 \%$ reported both.

Cox proportional hazard models, stratified by study and sex, and adjusted for age, with and without additional adjustment for alcohol, were used to estimate hazard ratios (HRs) associated with smoking (current $v$ never, and dose-response) for death due to UADTC and its subtypes. We also estimated HRs for overall UADTC by sex, geographical area (Asia/ANZ) and alcohol subgroups, and tested for effect modification by including interaction terms in the Cox models [13]. In order to avoid reporting unreliable results when the number of events was small, estimates of relative risk for UADTC subtypes are not reported for these subgroups. The effect of quitting smoking was estimated through HRs comparing ex-smokers with current smokers. All analyses used individual participant data.

The population attributable risk for mortality from UADTC associated with smoking were calculated for each country, for both males and females, using previously published recent prevalence estimates of the prevalence of smoking [10] and the formula [13]: PAR $=[\mathrm{P}(\mathrm{RR}-1)] /[1+\mathrm{P}(\mathrm{RR}-1)]$. Here, the RR was that found from APCSC.

\section{Results and Discussion}

Of the 44 studies in APCSC, 26 recorded current and past smoking and current drinking at baseline as well as deaths from UADTC. These 26 studies (19 from Asia) included 455,409 men and women (87\% from Asia; 32\% female) (Table 1). There were large differences in the percentage of smokers between the regions and sexes: $23 \%$ and $20 \%$ of men and women in ANZ and $59 \%$ and $5 \%$ of men and women in Asia, respectively. On average, smokers in ANZ smoked more cigarettes per day than those in Asia: 18 and 15 cigarettes per day in ANZ for men and women, respectively, compared with 15 and 11 in Asia. The percentage of individuals who reported that they consumed alcohol at study baseline also differed by region and by sex: $84 \%$ in men and $69 \%$ among women in ANZ, and $49 \%$ and $9 \%$ in men and women from Asia. During 2,906,013 person-years of follow up, there were 371 deaths from UADTC (176 lip, oral cavity or pharynx, 157 esophagus and 38 larynx; 74\% in Asia; 87\% male).

\subsection{Current Smoking and Risk of Mortality from UADTC}

Current smokers had more than twice the risk of mortality from UADTC, compared with never smokers: the HR was 2.36 (95\% confidence interval, CI: $1.77-3.15$ ), adjusted for age. The HR stayed the same after further adjustment for alcohol (Figure 1). For each subtype of UADTC, smoking was associated with a significant increase in the risk of mortality compared with never smoking. After 
adjusting for age and alcohol, the HR was: for lip, oral cavity or pharyngeal cancer, 2.14 (95\% CI: 1.43 - 3.19); esophageal cancer, 2.84 (95\% CI: 1.72 - 4.68); laryngeal cancer, 2.59 (95\% CI: 1.07 4.68). The association between smoking and overall UADTC death was much stronger in ANZ compared with Asia, and in women compared with men (Figure 1).

Table 1. Characteristics at baseline and details of follow-up, for all studies, by region.

\begin{tabular}{|c|c|c|c|c|c|c|c|c|c|c|c|c|c|c|c|}
\hline \multirow[t]{2}{*}{ Country } & \multirow[t]{2}{*}{ Study } & \multirow[t]{2}{*}{ Baseline } & \multirow[t]{2}{*}{$\begin{array}{l}\text { No. of } \\
\text { subjects }\end{array}$} & \multirow[t]{2}{*}{$\begin{array}{l}\text { Mean } \\
\text { age } \\
\text { (yrs) }\end{array}$} & \multirow[t]{2}{*}{$\begin{array}{l}\text { Fem } \\
\text {-ale } \\
(\%)\end{array}$} & \multicolumn{2}{|c|}{$\begin{array}{l}\text { Current } \\
\text { drinker } \\
\text { s } \\
\%\end{array}$} & \multicolumn{2}{|c|}{$\begin{array}{c}\text { Current } \\
\text { smokers } \\
(\%)\end{array}$} & \multicolumn{2}{|c|}{$\begin{array}{c}\text { Former } \\
\text { smoker } \\
\text { s } \\
(\%)\end{array}$} & \multicolumn{2}{|c|}{$\begin{array}{l}\text { Mean } \\
\text { cigarettes } \\
\text { per day }\end{array}$} & \multirow[t]{2}{*}{$\begin{array}{c}\text { Media } \\
\text { n } \\
\text { FU } \\
\text { (yrs) }\end{array}$} & \multirow[t]{2}{*}{$\begin{array}{l}\text { UADT } \\
\text { cancer } \\
\text { deaths }\end{array}$} \\
\hline & & & & & & $\mathrm{M}$ & $F$ & $\mathrm{M}$ & $\mathrm{F}$ & $\mathrm{M}$ & $\mathrm{F}$ & $\mathrm{M}$ & $F$ & & \\
\hline Australia & Busselton & 1966-81 & 7789 & 44.9 & 52 & 81 & 57 & 44 & 24 & 25 & 12 & 19 & 16 & 26.5 & 34 \\
\hline Australia & $\begin{array}{l}\text { Long. Study } \\
\text { of Aging }\end{array}$ & $1992-93$ & 1610 & 78.1 & 48 & 71 & 58 & 8 & 8 & 62 & 23 & 16 & 13 & 4.6 & 3 \\
\hline Australia & $\begin{array}{l}\text { National } \\
\text { Heart } \\
\text { Foundation }\end{array}$ & $1989-90$ & 9277 & 43.5 & 51 & 87 & 75 & 27 & 21 & 32 & 20 & 21 & 16 & 8.3 & 12 \\
\hline Australia & Newcastle & 1983-94 & 5929 & 51.7 & 50 & 85 & 65 & 28 & 18 & 37 & 18 & 20 & 18 & 8.9 & 13 \\
\hline Australia & Perth & 1978-94 & 10230 & 45.0 & 48 & 90 & 75 & 30 & 21 & 31 & 18 & 20 & 16 & 14.4 & 9 \\
\hline Australia & $\begin{array}{l}\text { WA AAA } \\
\text { Screenees }\end{array}$ & $1996-99$ & 12203 & 72.2 & 0 & 82 & - & 11 & - & 60 & - & 14 & - & 3.2 & 22 \\
\hline $\mathrm{NZ}$ & $\begin{array}{c}\text { Fletcher } \\
\text { Challenge }\end{array}$ & $1992-94$ & 10326 & 44.3 & 28 & 87 & 77 & 26 & 18 & 33 & 28 & 15 & 13 & 5.8 & 4 \\
\hline ANZ & Subtotal & 1966-99 & 57364 & 52.0 & 35 & 84 & 69 & 23 & 20 & 42 & 19 & 18 & 15 & 7.9 & 97 \\
\hline China & Anzhen & 1991 & 8378 & 53.8 & 55 & 39 & 3 & 51 & 10 & 9 & 2 & 15 & 10 & 4.3 & 5 \\
\hline China & $\begin{array}{l}\text { Fangshan } \\
\text { Guangzhou }\end{array}$ & 1991-92 & 2619 & 47.3 & 67 & 43 & 2 & 75 & 22 & 6 & 2 & 15 & 9 & 3.6 & 1 \\
\hline China & $\begin{array}{l}\text { Occupational } \\
\text { Seven Cities }\end{array}$ & $1985-98$ & 166695 & 41.5 & 22 & 27 & 4 & 60 & 1 & 1 & 0 & 15 & 12 & 7.3 & 146 \\
\hline China & Cohorts & 1987 & 10811 & 53.9 & 55 & 42 & 6 & 57 & 17 & 8 & 2 & - & - & 2.7 & 11 \\
\hline $\begin{array}{l}\text { China } \\
\text { Hong }\end{array}$ & Yunnan & 1992 & 6581 & 55.8 & 3 & 85 & 70 & 70 & 0 & 14 & 0 & 12 & - & 4.5 & 9 \\
\hline Kong & Hong Kong & $1985-91$ & 2983 & 78.6 & 57 & 24 & 8 & 29 & 11 & 41 & 18 & 13 & 8 & 2.5 & 5 \\
\hline Japan & $\begin{array}{l}\text { Akabane } \\
\text { Civil Service }\end{array}$ & $1985-86$ & 1834 & 54.5 & 56 & 62 & 5 & 62 & 1 & 21 & 0 & 23 & 9 & 11.0 & 1 \\
\hline Japan & Workers & 1990-92 & 9240 & 46.7 & 33 & 82 & 48 & 51 & 11 & 26 & 3 & - & - & 6.7 & 3 \\
\hline Japan & Hisayama & 1961 & 1601 & 56.1 & 56 & 70 & 8 & 76 & 17 & 4 & 1 & - & - & 24.6 & 4 \\
\hline Japan & Konan & $1987-95$ & 1226 & 51.7 & 55 & 78 & 23 & 62 & 5 & 14 & 1 & 22 & 11 & 6.4 & 3 \\
\hline Japan & Ohasama & 1992-93 & 2240 & 59.5 & 64 & 65 & 8 & 51 & 2 & 11 & 0 & - & - & 4.1 & 2 \\
\hline Japan & Saitama & $1986-90$ & 3615 & 54.5 & 62 & 77 & 33 & 63 & 8 & 21 & 2 & 22 & 13 & 11.0 & 9 \\
\hline Japan & Shibata & 1977 & 2350 & 56.9 & 58 & 72 & 9 & 72 & 4 & 6 & 0 & 20 & 10 & 20.0 & 10 \\
\hline Japan & $\begin{array}{l}\text { Shigaraki } \\
\text { Town }\end{array}$ & 1991-97 & 3730 & 57.1 & 59 & 70 & 19 & 59 & 8 & 22 & 2 & 22 & 13 & 4.4 & 4 \\
\hline Singapore & $\begin{array}{l}\text { Singapore } \\
\text { Heart }\end{array}$ & $1982-97$ & 2321 & 40.7 & 49 & 50 & 18 & 41 & 3 & 14 & 1 & - & - & 14.6 & 1 \\
\hline Singapore & $\begin{array}{l}\text { Singapore } \\
\text { NHS92 }\end{array}$ & 1992 & 3305 & 39.2 & 52 & 48 & 15 & 35 & 3 & 12 & 0 & - & - & 6.2 & 3 \\
\hline S. Korea & KMIC & 1992 & 160242 & 44.0 & 33 & 73 & 9 & 58 & 0 & 21 & 0 & - & - & 4.0 & 49 \\
\hline Taiwan & CVDFACTS & 1988-96 & 5729 & 47.2 & 55 & 16 & 1 & 48 & 1 & 7 & 0 & - & - & 6.0 & 2 \\
\hline Taiwan & Kinmen & 1993-97 & 2545 & 63.2 & 49 & 44 & 4 & 50 & 5 & 17 & 1 & - & - & 2.9 & 6 \\
\hline Asia & Subtotal & 1961-98 & 398045 & 44.6 & 32 & 49 & 9 & 59 & 5 & 11 & 1 & 15 & 11 & 5.3 & 274 \\
\hline Total & & 1961-99 & 455409 & 46.0 & 32 & 53 & 17 & 55 & 7 & 14 & 3 & 16 & 14 & 5.9 & 371 \\
\hline
\end{tabular}


Figure 1. Hazard ratios for death due to upper aero digestive tract cancer for current smokers compared with those who have never smoked by subgroups and overall.

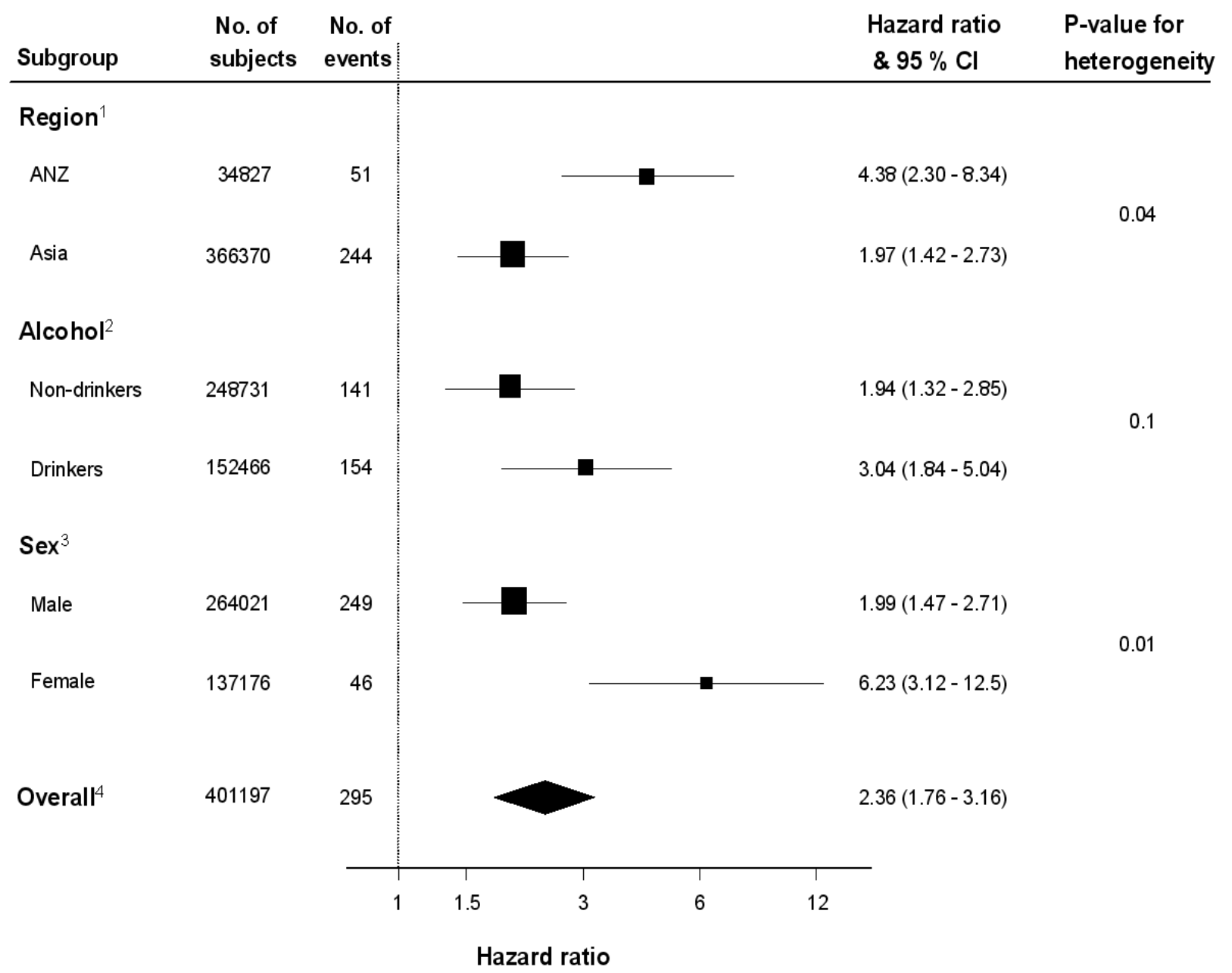

Black square = point estimate (with area proportional to statistical 'information', based on inverse of variance of the HR estimated for each subgroup) and horizontal line $=95 \%$ CI for observed effect in each subgroup and overall.

$1=$ adjusted for age and alcohol (analyses from Cox models which were stratified by sex and study);

2 = adjusted for age (stratified by sex and study);

$3=$ adjusted for age and alcohol (stratified by study);

$4=$ adjusted for age and alcohol (stratified by sex and study)

\subsection{Current Drinking and Smoking and UADTC}

The HR for current drinking, compared with not, was 1.33 (95\% CI: 1.03 - 1.73). However, after adjusting for current smoking, alcohol had very little association with the risk of mortality from UADTC: 1.01 (95\% CI: 0.80 - 12.7). Current smoking had a significant effect among both drinkers and non-drinkers (Figure 1). Although the effect of smoking was considerably higher among those who consumed alcohol, there was no strong evidence of an interaction $(\mathrm{p}=0.10)$, perhaps due to lack of information on the level of alcohol consumption. 


\subsection{Smoking and Risk of Mortality from UADTC in Former Smokers}

Overall, 48,134 individuals (62\% from Asia) reported at study baseline that they had quit smoking. During follow-up, a total of 70 (40\% from Asia) former smokers died of UADTC. The HR for mortality from UADTC, comparing ex-smokers with current smokers, was 0.92 (95\% CI: 0.66 - 1.27), adjusted for age and alcohol drinking. This HR differed by subtypes of UADTC: for lip, oral cavity or pharyngeal cancer, 0.99 (95\% CI: $0.58-1.69)$; esophageal cancer, 1.03 (95\% CI: $0.66-1.63$ ); and laryngeal cancer, 0.33 (95\% CI; $0.11-0.98)$.

Table 2. Dose-response association between current cigarette smoking and upper aero digestive tract cancers $(\mathrm{CPD}=$ cigarettes currently smoked per day, where known). All analyses stratified by sex and study.

\begin{tabular}{|c|c|c|c|c|}
\hline Cancer type & $\begin{array}{c}\text { No. of } \\
\text { subjects }\end{array}$ & $\begin{array}{l}\text { No. of } \\
\text { deaths }\end{array}$ & $\begin{array}{l}\text { Adjusted for age } \\
\text { HR and } 95 \% \text { CI }\end{array}$ & $\begin{array}{c}\text { Adjusted for age \& alcohol } \\
\text { HR and } 95 \% \text { CI } \\
\end{array}$ \\
\hline \multicolumn{3}{|c|}{ Lip, oral cavity or pharynx } & & \\
\hline Never-smoked & 142700 & 57 & 1 & 1 \\
\hline$<20 \mathrm{CPD}$ & 50077 & 34 & $1.83(1.14-2.95)$ & $1.86(1.15-3.00)$ \\
\hline$\geq 20 \mathrm{CPD}$ & 38785 & 43 & $2.32(1.47-3.65)$ & $2.37(1.49-3.78)$ \\
\hline \multicolumn{3}{|c|}{$\mathrm{P}$ for trend } & $<0.001$ & $<0.001$ \\
\hline \multicolumn{3}{|l|}{ Esophagus } & & \\
\hline Never-smoked & 142700 & 33 & 1 & 1 \\
\hline$<20 \mathrm{CPD}$ & 50077 & 17 & $2.74(1.37-5.49)$ & $2.52(1.25-5.07)$ \\
\hline$\geq 20 \mathrm{CPD}$ & 38785 & 25 & $3.89(1.99-7.60)$ & $3.40(1.71-6.76)$ \\
\hline \multicolumn{3}{|c|}{$\mathrm{P}$ for trend } & $<0.001$ & $<0.001$ \\
\hline \multicolumn{3}{|l|}{ Larynx } & & \\
\hline Never-smoked & 142700 & 7 & 1 & 1 \\
\hline$<20 \mathrm{CPD}$ & 50077 & 2 & $1.18(0.22-6.17)$ & $1.28(0.24-6.76)$ \\
\hline$\geq 20 \mathrm{CPD}$ & 38785 & 9 & $5.25(1.62-17.0)$ & $5.91(1.81-19.3)$ \\
\hline \multicolumn{3}{|c|}{ P for trend } & 0.005 & 0.003 \\
\hline \multicolumn{5}{|l|}{ Overall } \\
\hline Never-smoked & 142700 & 97 & 1 & 1 \\
\hline$<20 \mathrm{CPD}$ & 50077 & 53 & $2.03(1.38-2.97)$ & $2.01(1.37-2.95)$ \\
\hline$\geq 20 \mathrm{CPD}$ & 38785 & 77 & $2.88(2.01-4.11)$ & $2.83(1.96-4.09)$ \\
\hline \multicolumn{3}{|c|}{ P for trend } & $<0.001$ & $<0.001$ \\
\hline
\end{tabular}

\subsection{Dose-Response Relationship between Current Smoking and UADTC}

Of the 26 studies, 17 reported the number of cigarettes smoked per day at baseline, involving 231,562 study participants. There was evidence of a dose-response association between the number of cigarettes smoked per day and mortality from UADTC and its subtypes (Table 2). Individuals who smoked more than 20 cigarettes a day had approximately three times the risk of dying from UADTC 
compared with never smokers. However, there was evidence of a sex difference in the strength of this association: the HR for smoking $\geq 20$ cigarettes per day compared with never smoking was 2.27 (95\% CI: 1.77 - 2.90) in men versus 21.1 (95\% CI: 9.02 - 49.4) in women, after adjusting for age and alcohol; (Figure 2A). Similarly, significant differences were found between the regions (Figure 2B); the equivalent HRs were 5.03 (95\% CI: 2.70 - 9.36) in ANZ versus 2.30 (95\% CI: 1.77 - 2.99) in Asia.

Figure 2. Hazard ratios for death due to upper aero digestive tract cancer for current smokers by number of cigarettes smoked per day, compared with those who have never smoked. Lines show 95\% confidence limits; the arrow signifies that the upper end is off the scale. Hazard ratios are adjusted for age and alcohol.

(a) Analyses by sex (stratified by study)

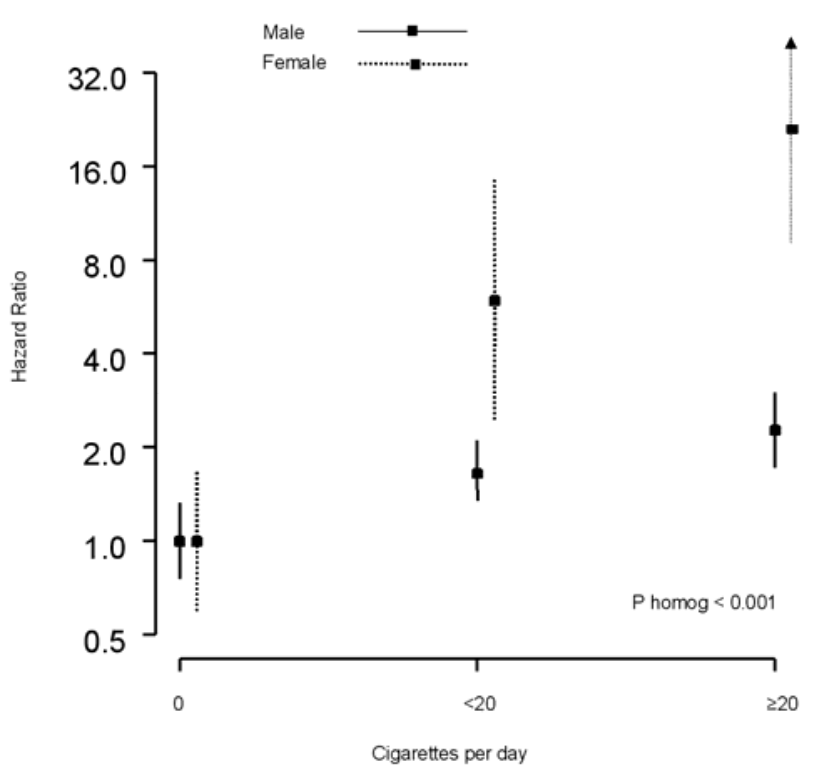

(b) Analyses by region (stratified by sex and study)

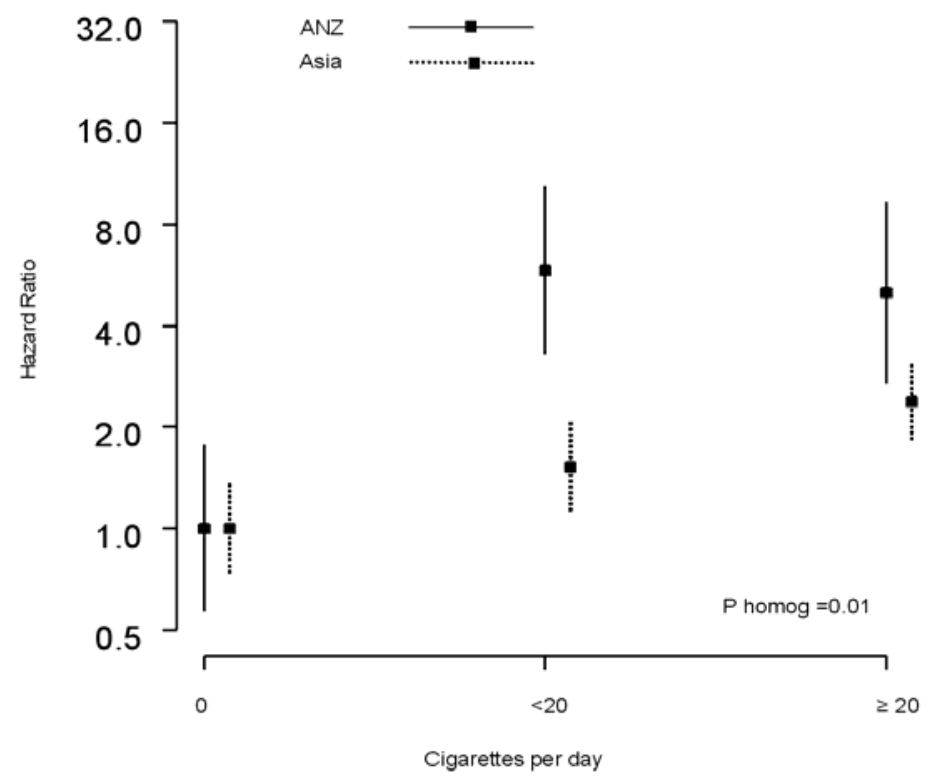




\subsection{Contribution of Smoking to Mortality from UADTC}

Figure 3 presents the population attributable fraction for males and females for UADTC caused by smoking for each country in the WHO Western Pacific and South-East Asian regions. The fraction of UADTC attributable to smoking ranged from $18-47 \%$ in males and from $1-45 \%$ in females.

\subsection{Discussion}

Analyses from this large dataset, with almost 400 deaths, confirm that smoking is strongly associated with the risk of mortality from UADTC in both Asia and ANZ. There was a significant dose-response association between the average number of cigarettes smoked daily and the risk for all subtypes of UADTC. Smoking had a stronger association with the risk of mortality from UADTC among female, compared with male, smokers. Although not statistically significant, the current study supports previous observations that concurrent alcohol consumption may exacerbate the effect of smoking on the risk of UADTC [7,14]: amongst non-drinkers, smoking doubled the risk of UADTC, whereas amongst drinkers it trebled the risk.

The findings of this study are consistent with earlier epidemiological evidence [15-23], but the estimated hazards are smaller than in some studies [18-23], especially those conducted in Western countries [20-23]. This may be due to differences in study design and the degree to which non-fatal events are included. But it may also signify a regional difference, since the Asian studies contributed $87 \%$ of participants, and $74 \%$ of events in APCSC, whilst the ANZ hazard ratio was significantly higher in this study. The lower excess risk for UADTC associated with smoking in Asia is likely to be due to the relative immaturity of the smoking epidemic across Asian countries [24], especially in China, where the habit only reached its peak in the mid-1990's [25-29]. Other potential contributing factors to the smaller relative risks associated with smoking observed in the Asian cohorts are the greater exposure among non-smokers to indoor air-pollution from wood-burning in homes [30] combined with extremely high levels of passive smoking, particularly in China where an estimated 450 million individuals are so exposed [31].

The APCSC estimates suggest a greater risk of mortality from UADTC among female smokers compared with male smokers, in agreement with a recent study in Japan [32], but opposite to the finding of the Swedish Smoking Survey [33], although the latter was based on few events (11 in women and 33 in men). Several epidemiological studies have found a statistically significant increase risk for lung cancer among female smokers compared with male smokers, although others have found no difference [34-39]. It is currently unclear which mechanisms mediate the reported increased susceptibility among female smokers to cancers of the lung and upper-aero digestive tract. Potential explanations include sex differences in smoking behaviours (such as the degree of inhalation, for example) or differences in the accuracy of self-reporting of smoking consumption between men and women. Alternatively, a role for female sex hormones in increasing the susceptibility of women to tobacco carcinogens has been suggested [34-38]. Clearly, further research is required to determine whether the difference in risk between men and women is real and if so, what is driving it. Answers to these two questions could have repercussions for the development of sex-specific smoking cessation 
programs, particularly in countries where the prevalence of smoking is on the increase in young women [40].

Figure 3. Population attributable risk (\%) of upper aero digestive tract cancer for smoking. Data are derived from representative surveys (years of studies given in parentheses).

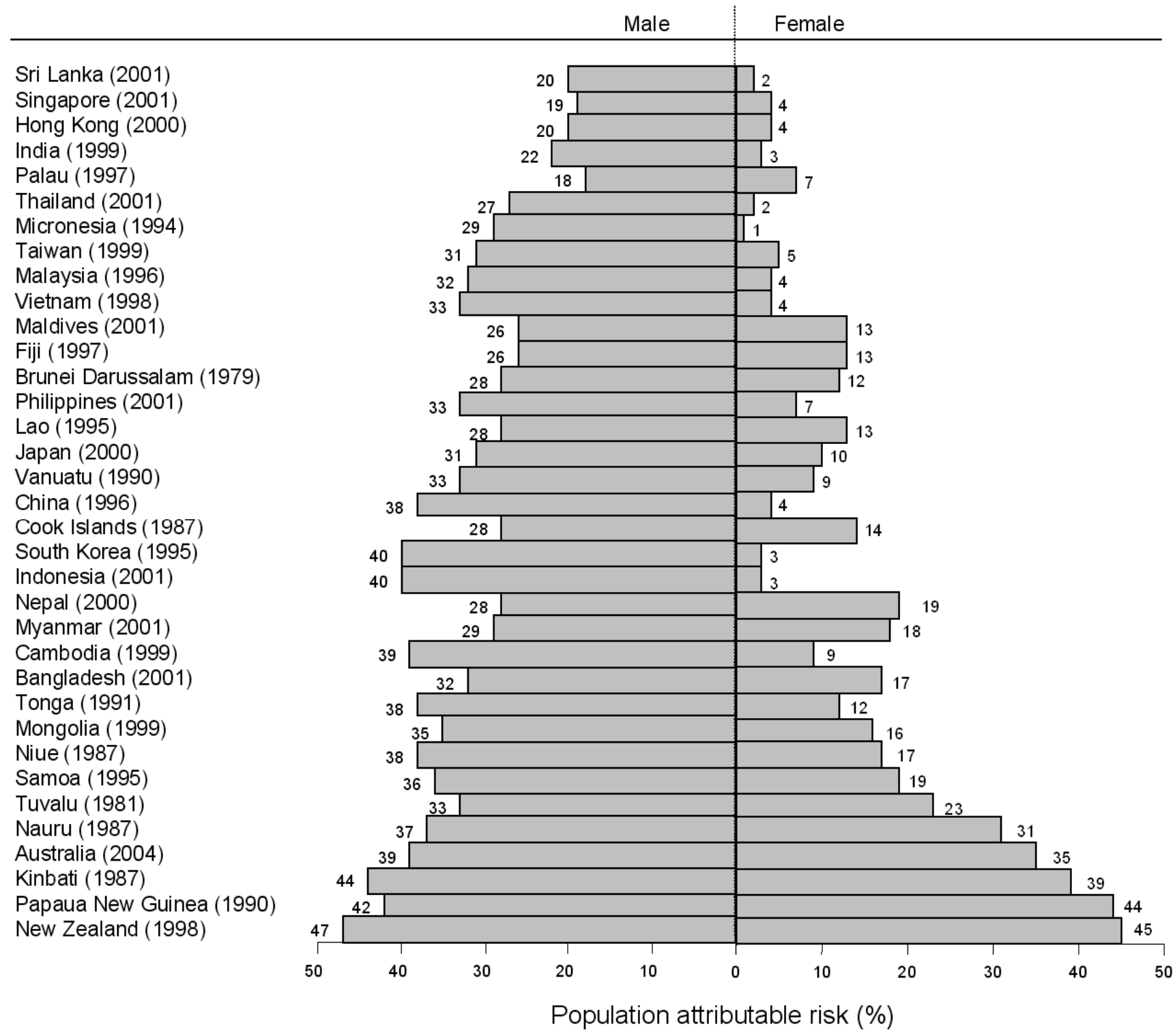

In contrast with an overview of studies that reported a reduction in risk of UADTC among former smokers compared with current smokers of $30 \%$ to $50 \%$ in the first five years and up to $70 \%$ after 10 years of quitting smoking [41], data from the current study failed to demonstrate a significant reduction in risk of dying from UADTC among former smokers compared with current smokers, except for laryngeal cancer. We believe that our inability to find a protective effect of quitting overall is most likely an artifact of the current situation in Asia where quitting is unusual, and those who have quit will have abstained for a relatively short time. However, differences in the distribution of subsidiary site cancers within the overall definition of UADTC could also play a role.

The main strength of the current analysis is the large number of events, which facilitated our ability to assess associations in subgroups. However, we were limited by lack of information on duration of 
smoking and age of uptake of smoking, which may well be important determinants of the risk of smoking cigarettes for UADTC. Our data on alcohol drinking were also limited to baseline measures of current drinking and also to whether or not the subject drank; there is evidence [7,14] of a doseresponse relationship between the amount of alcohol consumed and UADTC. Thus, we may have underestimated the true effect of drinking; there may be residual confounding due to our lack of data on the frequency of alcohol use. Furthermore, we had no data on changes in smoking and drinking status during follow-up. Although our analyses were restricted to deaths, the low five-year survival from UADTC [2-4], and the lack of systematic differences in excess risk found between previous studies that did [15,16,18,21-23] and did not [17,19,20] analyse non-fatal, as well as fatal, UADTC events, suggests that this has not introduced bias.

\section{Conclusions}

Findings from this study have clear implications for public health. For example, based on recent reports of the prevalence of smoking amongst men [10], and the effect of smoking found here, we estimate that $38 \%$ of male deaths from UADTC in China are attributable [13] to smoking. Effective tobacco control in the populous Asia Pacific region should prevent millions of deaths from UADTC, as well as other smoking-related outcomes, over the next few decades.

\section{Acknowledgements}

This paper is dedicated to the memory of Gary Andrews, whom we thank for his enthusiastic support of the APCSC.

Executive Committee: M. Woodward (Chair), R. Huxley, X. Fang, D.F. Gu, Y. Imai, T.H. Lam, W.H. Pan, A. Rodgers, I. Suh, H.C. Kim, H. Ueshima

Funding/Support: This project has received grants from the National Health and Medical Research Council of Australia, the University of Sydney and an unrestricted educational grant from Pfizer Inc. Alireza Ansary-Moghaddam was funded by a scholarship from Zahedan University of Medical Sciences and Alexandra Martiniuk was funded by a postdoctoral fellowship from the Canadian Institutes of Health Research.

Participating Studies and Principal Collaborators in APCSC: Aito Town: A. Okayama, H. Ueshima; H. Maegawa; Akabane: M. Nakamura, N. Aoki; Anzhen02: Z.S. Wu; Anzhen: C.H. Yao, Z.S. Wu; Australian Longitudinal Study of Aging: M. Luszcz; Australian National Heart Foundation: T.A. Welborn; Beijing Aging: Z. Tang; Beijing Steelworkers: L.S. Liu, J.X. Xie; Blood Donors' Health: R. Norton, S. Ameratunga, S. MacMahon, G. Whitlock; Busselton: M.W. Knuiman; CanberraQueanbeyan: H. Christensen; Capital Iron and Steel Company: X.G. Wu; CISCH: J. Zhou, X.H. Yu; Civil Service Workers: A. Tamakoshi; CVDFACTS: W.H. Pan; East Beijing: Z.L. Wu, L.Q. Chen, G.L. Shan; Electricity Generating Authority of Thailand: P. Sritara; Fangshan: D.F. Gu, X.F. Duan; Fletcher Challenge: S. MacMahon, R. Norton, G. Whitlock, R. Jackson; Guangzhou: Y.H. Li; 
Guangzhou Occupational: T.H. Lam, C.Q. Jiang; Hisayama: Y. Kiyohara, H. Arima, M. Iida; Hong Kong: J. Woo, S.C. Ho; Huashan: Z. Hong, M.S. Huang, B. Zhou (deceased); Kinmen: J.L. Fuh; Konan: H. Ueshima, Y. Kita, S.R. Choudhury; KMIC: I. Suh, S.H. Jee, I.S. Kim; Melbourne: G.G. Giles; Miyama: T. Hashimoto, K. Sakata; Newcastle: A. Dobson; Ohasama: Y. Imai, T. Ohkubo, A. Hozawa; Perth: K. Jamrozik, M. Hobbs, R. Broadhurst; Saitama: K. Nakachi; Seven Cities: X.H. Fang, S.C. Li, Q.D. Yang; Shanghai Factory Workers: Z.M. Chen; Shibata: H. Tanaka; Shigaraki Town: Y. Kita, A. Nozaki, H. Ueshima; Shirakawa: H. Horibe, Y. Matsutani, M. Kagaya; Singapore Heart: K. Hughes, J. Lee; Singapore NHS92: D. Heng, S.K. Chew; Six Cohorts: B.F. Zhou, H.Y. Zhang; Tanno/Soubetsu: K. Shimamoto, S. Saitoh; Tianjin: Z.Z. Li, H.Y. Zhang; Western Australia AAA Screenees: P. Norman, K. Jamrozik; Xi'an: Y. He, T.H. Lam; Yunnan: S.X. Yao.

\section{References}

1. Ferlay, J.; Bray, F.; Pisani, P.; Parkin, D.M. GLOBOCAN 2002, Cancer Incidence, Mortality and Prevalence Worldwide. IARC Cancer Base No 5. Version 2.0, IARC Press: Lyon, France, 2004.

2. Parkin, D.M.; Bray, F.; Ferlay, J.; Pisani, P. Global cancer statistics, 2002. C.A. Cancer J. Clin. 2005, 55, 74-108.

3. Gluckman, J.L.; Farrell, M. In Internal Medicine, $5^{\text {th }}$ Ed.; Stein, J.H., Ed.; Mosby Inc: St, Louis, USA, 1998, Chapter 98.

4. Schottenfeld, D.; Fraumeni, F. Cancer epidemiology and prevention, $3^{\text {rd }}$ Ed.; Oxford University Press: New York, USA, 2006.

5. Ezzati, M.; Henley, S.J.; Lopez, A.D.; Thun, M.J. Role of smoking in global and regional cancer epidemiology, current patterns and data needs. Int. J. Cancer 2005, 116, 963-971.

6. World Health Organization. WHO Global Status Report on Alcohol 2004. WHO: Geneva, Switzerland.

7. Zeka, A.; Gore, R.; Kriebel, D. Effects of alcohol and tobacco on aero digestive cancer risks, a meta-regression analysis. Cancer Cause. Control 2003, 14, 897-906.

8. Jha, P.; Paccaud, F.; Nguyen, S. Tobacco control in developing countries. Curbing the epidemic; Chapter 19. World Bank, Oxford University Press: New York, USA, 2000.

9. Yang, G.; Fan, L.; Tan, J.; Qi, G.; Zhang, Y.; Samet, J.M.; Taylor, C.E.; Becker, K.; Xu, J. Smoking in China, findings of the 1996 National Prevalence Survey. JAMA 1999, 282, 1247-1253.

10. Martiniuk, A.L.; Lee, C.M.; Lam, T.H.; Huxley, R.; Suh, I.; Jamrozik, K.; Gu, D.F.; Woodward, M. The fraction of ischaemic heart disease and stroke attributable to smoking in the WHO Western Pacific and South-East Asian regions. Tob. Control 2006, 15, 181-188.

11. Samet, J.M.; Yoon, S.-Y. Women and the Tobacco Epidemic. World Health Organisation: Geneva, Switzerland, 2001.

12. Woodward, M.; Barzi, F.; Martiniuk, A.; Fang, X.; Gu, D.F.; Imai, Y.; Lam, T.H.; Pan, W.H.; Rodgers, A.; Suh, I.; Jee, S.H.; Ueshima, H.; Huxley, R. Cohort profile, The Asia Pacific Cohort Studies Collaboration. Int. J. Epidemiol. 2006, 35, 1412-1416.

13. Woodward M. Epidemiology, study design and data analysis. $2^{\text {nd }}$ Ed.; Chapman and Hall/CRC Press: Boca Raton, USA, 2005. 
14. Bagnardi, V.; Blangiardo, M.; La Vecchia, C.; Corrao, G. Alcohol consumption and the risk of cancer, a meta-analysis. Alcohol Res. Health 2001, 25, 263-270.

15. Nordlund, L.A.; Carstensen, J.M.; Pershagen, G. Cancer incidence in female smokers, a 26-year follow-up. Int. J. Cancer 1997, 73, 625-628.

16. Lindblad, M.; Rodriguez, L.A.; Lagergren, J. Body mass, tobacco and alcohol and risk of esophageal, gastric cardia, and gastric non-cardia adenocarcinoma among men and women in a nested case-control study. Cancer Cause. Control 2005, 16, 285-294.

17. Jiang, J.M.; Zeng, X.J.; Chen, J.S.; Ping, Z.; Li, J.Y.; Zhang, K.L.; Wu, Y.P.; Liu, B.Q. Smoking and mortality from esophageal cancer in China: a large case-control study of 19,734 male esophageal cancer deaths and 104,846 living spouse controls. Int. J. Cancer 2006, 119, 1427-1432.

18. Sakata, K.; Hoshiyama, Y.; Morioka, S.; Hashimoto, T.; Takeshita, T.; Tamakoshi, A. Smoking, alcohol drinking and esophageal cancer, findings from the JACC Study. J. Epidemiol. 2005, 15, 212-219.

19. Jee, S.H.; Samet, J.M.; Ohrr, H.; Kim, J.H.; Kim, I.S. Smoking and cancer risk in Korean men and women. Cancer Cause. Control 2004, 15, 341-348.

20. McLaughlin, J.K.; Hrubec, Z.; Blot, W.J.; Fraumeni, J.F., Jr. Smoking and cancer mortality among U.S. veterans, a 26-year follow-up. Int. J. Cancer 1995, 60, 190-193.

21. La Vecchia, C.; Bidoli, E.; Barra, S.; D'Avanzo, B.; Negri, E.; Talamini, R.; Franceschi, S. Type of cigarettes and cancers of the upper digestive and respiratory tract. Cancer Cause. Control 1990, 1, 69-74.

22. Bosetti, C.; Gallus, S.; Franceschi, S.; Levi, F.; Bertuzzi, M.; Negri, E.; Talamini, R.; La Vecchia, C. Cancer of the larynx in non-smoking alcohol drinkers and in non-drinking tobacco smokers. Br. J. Cancer 2002, 87, 516-518.

23. Castellsague, X.; Quintana, M.J.; Martinez, M.C.; Nieto, A.; Sánchez, M.J.; Juan, A.; Monner, A.; Carrera, M.; Agudo, A.; Quer, M.; Muñoz, N.; Herrero, R.; Franceschi, S.; Bosch, F.X. The role of type of tobacco and type of alcoholic beverage in oral carcinogenesis. Int. J. Cancer 2004, 108, 741-749.

24. Lopez, A.D.; Collishaw, N.E.; Piha, T. A descriptive model of the cigarette epidemic in developed countries. Tob. Control 1994, 3, 242-247.

25. Wynder, E.; Fujita, Y.; Harris, R.E.; Hirayama, T.; Hiyama, T. Comparative epidemiology of cancer between the United States and Japan, a second look. Cancer 1991, 67, 746-763.

26. Peto, R.; Chen, Z.M.; Boreham, J. Tobacco - the growing epidemic. Nature Med. 1999, 5, 15-17.

27. Zhang, H.; Cai, B. The impact of tobacco on lung health in China. Respirology 2003, 8, 17-21.

28. Ando, M.; Wakai, K.; Seki, N.; Tamakoshi, A.; Suzuki, K.; Ito, Y.; Nishino, Y.; Kondo, T.; Watanabe, Y.; Ozasa, K.; Ohno, Y. Attributable and absolute risk of lung cancer death by smoking status. Findings from the Japan Collaborative Cohort Study. Int. J. Cancer 2003, 105, 249-254.

29. Marugame, T.; Sobue, T.; Satoh, H.; Komatsu, S.; Nishino, Y.; Nakatsuka, H.; Nakayama, T.; Suzuki, T.; Takezaki, T.; Tajima, K.; Tominaga, S. Lung cancer death rates by smoking status. Comparison of the Three-Prefecture Cohort study in Japan to the Cancer Prevention Study II in the USA. Cancer Sci. 2005, 96, 120-126. 
30. Pintos, J.; Franco, E.L.; Kowalski, L.P.; Oliveira, B.V.; Curado, M.P. Use of wood stoves and risk of cancers of the upper aero-digestive tract, a case-control study. Int. J. Epidemiol. 1998, 27, 936-940.

31. Ministry of Health, Peoples' Republic of China. 2007 China Tobacco Control Report-Create a Smoke-Free Environment; Enjoy a Healthy Life. Office of the Leading Small Group for Implementation of the Framework Convention on Tobacco Control: Beijing, China, May 2007.

32. Ide, R.; Mizoue, T.; Fujino, Y.; Hoshiyama, Y.; Sakata, K.; Tamakoshi, A.; Yoshimura, T. Cigarette smoking, alcohol drinking, and oral and pharyngeal cancer mortality in Japan. Oral Dis. 2008, 14, 314-319.

33. Nilsson, S.; Carstensen, J.M.; Pershagen, G. Mortality among male and female smokers in Sweden, a 33 year follows up. J. Epidemiol. Community Health 2001, 55, 825-830.

34. Zang, E.A.; Wynder, E.L. Differences in lung cancer risk between men and women, examination of the evidence. J. Natl. Cancer Inst. 1996, 88, 183-192.

35. Osann, K.E.; Anton-Culver, H.; Kurosaki, T.; Taylor, T. Sex differences in lung-cancer risk associated with cigarette smoking. Int. J. Cancer 1993, 54, 44-48.

36. Wynder, E.L.; Muscat, J.E. The changing epidemiology of smoking and lung cancer histology. Environ. Health Perspect.1995, 8, 143-148.

37. Gao, Y.T.; Blot, W.J.; Zheng, W.; Ershow, A.G.; Hsu, C.W.; Levin, L.I.; Zhang, R.; Fraumeni, J.F., Jr. Lung cancer among Chinese women. Int. J. Cancer. 1987, 40, 604-609.

38. Taioli, E.; Wynder, E.L. Endocrine factors and adenocarcinoma of the lung in women. J. Natl. Cancer Inst. 1994, 86, 869-870.

39. Bain, C.; Feskanich, D.; Speizer, F.E.; Thun, M.; Hertzmark, E.; Rosner, B.A.; Colditz, G.A. Lung cancer rates in men and women with comparable histories of smoking. J. Natl. Cancer Inst. 2004, 96, 826-834.

40. Mackay, J.; Eriksen, M.; Shafey, O. The Tobacco Atlas, $2^{\text {nd }}$ Ed.; American Cancer Society: Atlanta, Georgia, USA, 2006.

41. Bosetti, C.; Gallus, S.; Garavello, W.; La Vecchia, C. Smoking cessation and the risk of oesophageal cancer. An overview of published studies. Oral Oncol. 2006, 42, 957-964.

(C) 2009 by the authors; licensee Molecular Diversity Preservation International, Basel, Switzerland. This article is an open-access article distributed under the terms and conditions of the Creative Commons Attribution license (http://creativecommons.org/licenses/by/3.0/). 